\title{
Development of a biomaterial based on HAP/TiOy nanocomposite with different stoichiometry
}

\author{
S. V. Rempel ${ }^{1,2,}$, A. A. Valeeva ${ }^{1,2}$, E. A. Bogdanova ${ }^{1}$, N. A. Sabirzyanov ${ }^{1}$ \\ †svetlana_rempel@ihim.uran.ru
}

\begin{abstract}
${ }^{1}$ Institute of Solid State Chemistry, UB of the RAS, 91 Pervomaiskaya st., 620990, Yekaterinburg, Russia
${ }^{2}$ Ural Federal University named after the First President of Russia B.N. Eltsin, 19 Mira st., 620002, Yekaterinburg, Russia
\end{abstract}

\begin{abstract}
At present, composite materials based on bioactive hydroxyappatite (HAP) are intensively developed. To achieve better mechanical properties, different additives are used, for example, titanium, zirconium, etc. In the present study, a dispersionhardened composite material based on nanocrystalline HAP and nanocrystalline titanium monoxide $\left(\mathrm{TiO}_{y}, y=0.92,1.23\right)$ is prepared by low temperature annealing in vacuum. As an additive, titanium monoxide with different mass ratios and stoichiometries ( 10 or 20 mass $\%$ of substoichiometric $\mathrm{TiO}_{0.92}$ or superstoichiometric $\mathrm{TiO}_{1.23}$ ) is used. For the preparation of nanocrystalline powders and mixing of initial components, a planetary ball mill was used. According to scanning electron microscopy (SEM) data, using of the ball milling for mechanical mixing of nanopartilces allows one to prepare denser material with a particle shape, which facilitates cold pressing and sintering. It has been established that introducing of the $\mathrm{TiO}_{y}$ additive leads to a reduction of the starting temperature of the composite material hardening by 200 to $250^{\circ} \mathrm{C}$. The phase composition and properties of the end product (microhardness, density) depend on the stoichiometry and on the amount of additives. For the content of 20 mass $\%$ of substoichiometric $\mathrm{TiO}_{0.92}$ phases $\mathrm{Ti}_{4.5} \mathrm{O}_{5}$ and $\mathrm{Ti}_{6} \mathrm{O}_{11}$ are found by means of XRD studies. The phase $\mathrm{Ti}_{4.5} \mathrm{O}_{5}$ is an ordered phase and is more stable as compared to other phases of Ti-O system., while the phase $\mathrm{Ti}_{6} \mathrm{O}_{11}$ has easy slip crystallographic planes. Presence of such two phases positively influences on mechanical properties of the composite. According to SEM, BET and microhardness data, the composites prepared are nanodispersed ones and show an increased density and microhardness as compared to HAP without additives.
\end{abstract}

Keywords: hydroxyapatite, titanium monoxide, grinding, microhardness.

\section{Разработка биоматериала на основе нанокомпозита ГАП/ТiOу с разной стехиометрией}

\author{
Ремпель С. В. ${ }^{1,2,}$, Валеева А. А. ${ }^{1,2}$, Богданова Е. А. ${ }^{1}$, Сабирзянов Н. А. ${ }^{1}$ \\ ${ }^{1}$ Институт химии твёрдого тела УрО РАН, ул. Первомайская 91, 620990, Екатеринбург, Россия \\ ${ }^{2}$ Уральский федеральный университет имени первого Президента России Б. Н. Ельцина, ул. Мира 19, 620002, \\ Екатеринбург, Россия
}

В настоящее время активно разрабатываются композиционные материалы на основе биоактивного и биорезорбируемого гидроксиапатита (ГАП). Для улучшения механических свойств ГАП применяются различные добавки, в частности, титан, цирконий и т.д. В данной работе методом низкотемпературного отжига в вакууме получен дисперсионно-упрочнённый композиционный материал на основе нанокристаллических ГАП и монооксида титана $\left(\mathrm{TiO}_{y}, y=0.92,1.23\right)$. В качестве добавки был использован монооксид титана с разным массовым содержанием и стехиометрией (10 или 20 масс. \% достехиометрического $\mathrm{TiO}_{0.92}$ или сверхстехиометрического ТіО 1.23 ). Для получения нанокристаллических порошков и смешивания исходных компонентов была использована планетарная шаровая мельница. Согласно результатам растровой электронной микроскопии (РЭМ) такой способ позволяет уже при механическом смешивании наночастиц исходных компонентов получить более плотный материал с формой частиц, облегчающей холодное прессование и спекание. Установлено, что введение в ГАП добавки ТіО приводит к понижению начальной температуры упрочнения композиционного материала на $200-250^{\circ} \mathrm{C}$. Фазовый состав и свойства конечной керамики (микротвердость, плотность) зависят от стехиометрии и содержания добавок. Методом рентгеновской дифракции в композиционном материале ГАП/20 масс. \% $\mathrm{TiO}_{0.92}$ обнаружены фазы $\mathrm{Ti}_{4.5} \mathrm{O}_{5}$ и $\mathrm{Ti}_{6} \mathrm{O}_{11}$. Фаза $\mathrm{Ti}_{4.5} \mathrm{O}_{5}$ является упорядоченной и более стабильной по сравнению с другими фазами системы Ti-O, а фаза Тi ${ }_{6} \mathrm{O}_{11}$ отличается наличием кристаллографических плоскостей легкого скольжения. Наличие таких фаз положительно сказывается на механических свойствах материала. Согласно данным РЭМ, БЭТ и данным по микротвердости, полученные композиты являются нанодисперсными и превосходят ГАП без добавок по плотности и микротвердости.

Ключевые слова: гидроксиапатит, монооксид титана, размол, отжиг, микротвердость. 


\section{1. Введение}

Новые направления развития биотехнологии и инженерии костной ткани основаны на разработке и изучении материалов, позволяющих создавать остеоконструктивный матрикс [1] и создающих необходимые стимулы для остеогенеза. Одним из материалов, наиболее подходящих для этой цели, является гидроксиапатит $\left(\mathrm{Ca}_{10}\left(\mathrm{PO}_{4}\right)_{6}(\mathrm{OH})_{2}(\right.$ ГАП $)$. Механические свойства керамики из ГАП не всегда отвечают заданным требованиям. Поэтому для улучшения характеристик композиционных материалов на основе ГАП используют упрочняющие добавки.

Стехиометрия, как основного материала, так и добавок, играет существенную роль в процессах, протекающих при изготовлении и использовании композитов. Так, при использовании различных методов синтеза ГАП стремятся к стехиометрическому составу $\mathrm{Ca} / \mathrm{P}=1.67$, поскольку в костной ткани соотношение $\mathrm{Ca} / \mathrm{P}$ близко к этому значению. По результатам исследований $[2,3]$ ГАП с соотношением $\mathrm{Ca} / \mathrm{P}=1.67$ является более стабильным к тепловому воздействию и растворению, а керамика на его основе имеет наилучшие показатели по механическим характеристикам, плотности, твердости.

Для модификации композита из ГАП часто используется титан и его оксиды. Титан является биоинертным металлом, кроме того авторы $[5,6]$ показали, что ГАП с внедрёнными ионами титана (Ті модифицированный ГАП) проявляет не только фотокаталитическую активность, но и бактерицидный эффект.

Нанокерамика обладает рядом преимуществ по сравнению с обычной керамикой благодаря повышенной прочности и биоактивности. Важным свойством нанокерамики является особенность поверхности, поскольку она непосредственно влияет на вышеуказанные свойства $[7,8]$.

В настоящей работе для улучшения механических свойств ГАП использовали монооксид титана $\mathrm{TiO}_{y}$ с разным массовым содержанием и стехиометрией (10 или 20 масс. \% $\mathrm{TiO}_{0.92}$ и $\mathrm{TiO}_{1.23}$ ). Для получения нанокомпозитов были использованы нанопорошки ГАП и $\mathrm{TiO}_{y}$.

\section{2. Материалы}

Кристаллический ГАП стехиометрического состава получен осаждением из растворов гидроксида кальция и фосфорной кислоты [9]. Морфологию всех порошков изучали методом растровой электронной микроскопии (РЭМ) высокого разрешения на микроскопе ZEISS Ultra 55. Рентгено-дифракционные исследования порошков выполнены на автодифрактометре STADI-P (STOE, Германия). Фазовый анализ рентгенограмм проведен с помощью программы Powder Cell 2.4. Для идентификации фаз использовали «Базу порошковых стандартов - ICDD PDF2» (ICDD, USA, Release 2009).

Микрокристаллические порошки монооксида титана $\mathrm{TiO}_{y}$ синтезированы методом твердофазного спекания в вакууме из смеси порошков металлического титана $\mathrm{Ti}$ и диоксида титана $\mathrm{TiO}_{2}$, проведена аттестация образцов монооксида титана по химическому и фазовому составу, степени гомогенности и типу кристаллической структуры [10].

Нанокристаллический $\mathrm{TiO}_{\text {y }}$ был получен фрагментацией крупнокристаллического порошка монооксида титана в шаровой планетарной мельнице Retsch PM 200. Для получения нанопрошков длительность размола составила 480 минут. Изменение структуры нанокристаллического $\mathrm{TiO}_{y}$ при изменении температуры описано в работе [11].

Смешивание наночастиц монооксида титана с разным массовым содержанием и стехиометрией (10 или 20 масс. \% достехиометрического $\mathrm{TiO}_{0.92}$ и сверхстехиометрического $\mathrm{TiO}_{1.23}$ ) и ГАП проведено в планетарной шаровой мельнице Retsch PM 200 в течение 480 минут при тех же условиях.

Методом Брунауэра, Эммета и Теллера (БЭТ), (Gemini VII 2390 V1.03 (V1.03 t)) измерена удельная поверхность образцов. Пикнометрическая плотность исходных порошков и композитов измерена с помощью гелиевого пикнометра AccuРус II 1340 при комнатной температуре. Для прессования использовался ручной гидравлический пресс (КФ3, 1975г; с максимальным рабочим давлением 4 т). Таблетки диаметром 10 мм и массой 0.44-1.0 г прессовались без выдержки с максимальным давлением 20 МПа в стальной пресс-форме. Измерение микротвердости всех образцов проводилось на микротвердомере ПМТ-3М с нагрузкой $0.98 \mathrm{H}$ и временем нагружения 10 с. Поверхность образцов была предварительно отполирована на шлифовальной машине с тарельчатым кругом TG 125/E.

Таблетки отжигались в вакуумированных $\left(10^{-3}\right.$ Па) кварцевых ампулах при температурах $400^{\circ} \mathrm{C}$ и $600^{\circ} \mathrm{C}$ в течение 4 часов в печи SNOL6.7/1300, нагрев печи проводился со скоростью $100^{\circ} \mathrm{C} /$ час, охлаждение до комнатной температуры проводилось с печью.

\section{3. Результаты и обсуждение}

По результатам рентгенофазового анализа (РФА), синтезированный ГАП обладает высокой степенью кристалличности и имеет гексагональную структуру с пространственной группой P6-3/m (PDF No.: 01-073-8417).

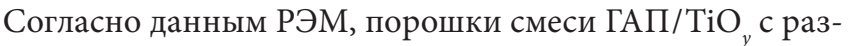
ным массовым содержанием и стехиометрией $\mathrm{TiO}_{y}$ по морфологии напоминают нанопорошок $\mathrm{TiO}_{y}$ и представляют собой слипшиеся наночастицы с минимальным размером частиц около 20 - 30 нм.

В результате дегазации ГАП и композитов установлено, что убыль массы композитов ГАП/ТіОу меньше убыли массы чистого ГАП (Табл. 1) что свидетельствует о меньшей пористости композитов. Уже при механическом смешивании наночастиц исходных компонентов в планетарной шаровой мельнице удаётся получить более плотный материал с формой частиц, облегчающей холодное прессование и спекание.

Согласно работе [12], максимальная плотность керамики на основе ГАП достигается при температуре $1250-1300^{\circ} \mathrm{C}$. Понижение температуры отжига позволит снизить присутствие нежелательных в ряде случаев примесей - дефектного апатита и оксиапатита кальция, 
Табл. 1. Относительное уменьшение массы, размеров и изменение плотности чистого и армированного ГАП после отжига при разных температурах.

Table 1. Relative reduction of mass, sizes and density change of the initial HAp composites after annealing at different temperatures.

\begin{tabular}{|c|c|c|c|c|c|c|}
\hline \multirow{2}{*}{$\begin{array}{l}\text { Содержание добавок в композите } \\
\text { Compound or composite }\end{array}$} & \multicolumn{2}{|c|}{$\begin{array}{l}\Delta m, \% \text { после отжига } \\
\Delta m, \% \text { after annealing }\end{array}$} & \multicolumn{2}{|c|}{$\begin{array}{l}\Delta h, \% \text { после отжига } \\
\Delta h, \% \text { after annealing }\end{array}$} & \multicolumn{2}{|c|}{$\begin{array}{c}\text { Плотность, г/ } \mathrm{cm}^{3} \\
\text { Density, } \mathrm{g} / \mathrm{cm}^{3}\end{array}$} \\
\hline & $400^{\circ} \mathrm{C}$ & $600^{\circ} \mathrm{C}$ & $400^{\circ} \mathrm{C}$ & $600^{\circ} \mathrm{C}$ & $400^{\circ} \mathrm{C}$ & $600^{\circ} \mathrm{C}$ \\
\hline $\begin{array}{c}\text { ГАП } \\
\text { (без добавок) } \\
\text { НАр initial } \\
\text { without additions }\end{array}$ & 1.33 & 2.05 & 2.48 & 2.31 & 2.97 & 2.95 \\
\hline $10 \% \mathrm{TiO}_{0.92}+\mathrm{HAp}$ & 1.41 & 1.73 & 0 & 2.35 & 3.06 & 3.07 \\
\hline $20 \% \mathrm{TiO}_{0.92}+\mathrm{HAp}$ & 1.03 & 1.77 & 1.00 & 1.59 & 3.19 & 3.29 \\
\hline $10 \% \mathrm{TiO}_{1.23}+\mathrm{HAp}$ & 1.78 & 1.81 & 0 & 0 & 3.07 & 3.10 \\
\hline $20 \% \mathrm{TiO}_{1.23}+\mathrm{HAp}$ & 1.17 & 0.90 & 0 & 0 & 3.03 & 3.22 \\
\hline
\end{tabular}

* $\Delta d=10 \%$ для всех образцов

$\star \Delta d=10 \%$ for all samples

интенсивное образование которых имеет место при температурах, превышающих $500^{\circ} \mathrm{C}$. ГАП, полученный осаждением из растворов, склонен к разложению при температурах выше $800^{\circ} \mathrm{C}$ [12]. Выбранные в настоящей работе температуры отжига $\left(400\right.$ и $\left.600^{\circ} \mathrm{C}\right)$ позволили избежать разложения ГАП, т.е. сохранить его биологическую активность и создать условия для процессов диффузии и упрочнения композитов.

Одним из наиболее важных процессов, оказывающих влияние на свойства керамики, является уплотнение материала, связанное с изменением количества, размера и формы пор. На рис. 1 представлена зависимость микротвёрдости от температуры отжига. Анализ данных показывает, что при использовании монооксида титана в качестве добавки удалось получить композиты, превосходящие примерно на 15\% по плотности и до 10\% по микротвердости ГАП без добавок.

Фазовый состав, микротвердость и плотность композитов, полученных при разных температурах отжига, зависят от стехиометрии и содержания добавок. Максимальная плотность достигнута для состава ГАП/ $\mathrm{TiO}_{0.92}$ 20 масс. \%, а максимальное значение микротвердости - для состава ГАП/ $\mathrm{TiO}_{1.23} 20$ масс. \% после отжига при $600^{\circ} \mathrm{C}$.

Анализ морфологии композитов с помощью РЭМ показал присутствие спёкшихся либо частично спёкшихся частиц размером от 50 нм до 1 мкм уже после отжига при $400^{\circ} \mathrm{C}$. Наряду со спёкшимися частицами присутствуют «мостики», соединяющие отдельные частицы. Наблюдается кристаллизация вторичных стержневидных кристаллов ГАП в порах и промежутках между агломератами. По данным [13] такая кристаллизация ведет к упрочнению керамики.

После отжига при $600^{\circ} \mathrm{C}$ уменьшилось количество пор, микроструктура стала более плотной (рис. 2, приведены наиболее типичные примеры). Агломераты состоят из спёкшихся частиц размерами 20-40 нм, спекание не приводит к росту частиц, т.е. наносостояние композитов после термообработки сохраняется.
Обнаружено, что отжиг композитов в вакуумированных ампулах при 400 и $600^{\circ} \mathrm{C}$ в течение 4 -х часов приводит к формированию различных фаз в зависимости от состава исходной смеси. Отжиг композитов с 10 масс. \% добавок $\mathrm{TiO}_{0.92}$ и $\mathrm{TiO}_{1.23}$ при $400^{\circ} \mathrm{C}$ не приводит к изменению фазового состава. При содержании 20 масс. \% $\mathrm{TiO}_{1.23}$ на рентгенограмме обнаружено слабое гало, соответствующее фазе диоксида титана - рутилу, что свидетельствует о начале окисления сверхстехиометрического монооксида титана. После отжига при температуре $600^{\circ} \mathrm{C}$ в течение 4 часов во всех образцах обнаружено изменение фазового состава. Кубический монооксид титана $\mathrm{TiO}_{y}$ окислился до диоксида титана,

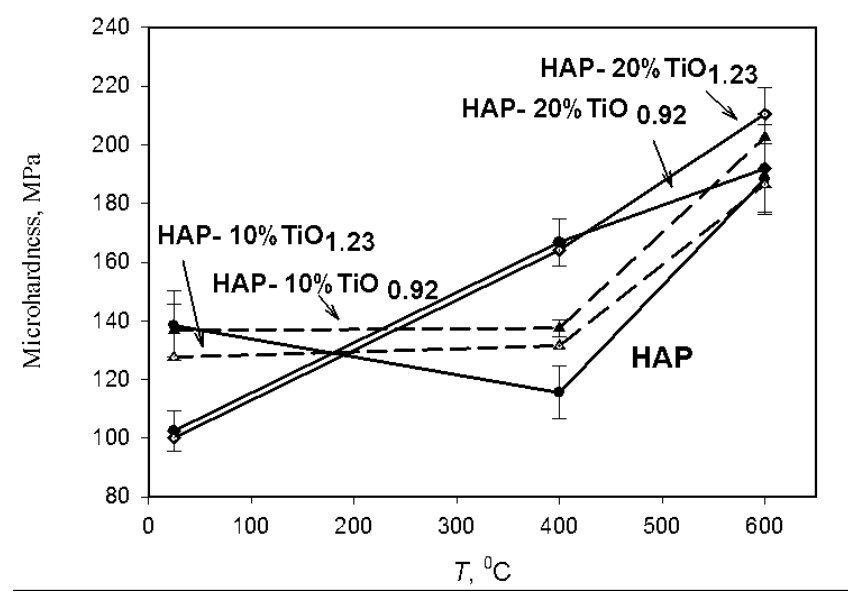

Рис. 1. Зависимость микротвердости от температуры отжига для разных составов: сплошные линии - HAp/20 mass \% of TiO, пунктирные линии НAp/10 mass \% of TiOy; закрытые и открытые символы обозначают достехиометрический и сверхстехиометрический $\mathrm{TiO}_{y}$, соответственно.

Fig. 1. The dependence of the microhardness on the temperature of annealing for different compositions: closed and opened symbols are used for substoichiometric and superstoichiometric $\mathrm{TiO}_{y}$, respectively. 
причем $\mathrm{TiO}_{2}$ содержится преимущественно в виде рутила. При 20 масс. \% достехиометрического $\mathrm{TiO}_{0.92}$ поступающего кислорода в композите оказалось недостаточно для полного окисления до диоксида титана и образовались промежуточные фазы $\mathrm{Ti}_{4.5} \mathrm{O}_{5}$ и $\mathrm{Ti}_{6} \mathrm{O}_{11}$ и, частично $\mathrm{TiO}_{2}$ в форме анатаза (рис. 3 ).

Исключение составляет композит с составом ГАП/20 масс. \% $\mathrm{TiO}_{0.92}$, содержащий промежуточные фазы $\mathrm{Ti}_{4.5} \mathrm{O}_{5}$ и $\mathrm{Ti}_{6} \mathrm{O}_{11}$. В нем не содержится фаза рутила, $\mathrm{TiO}_{2}$ присутствует только в форме анатаза. Вероятно, содержание промежуточных фаз и отсутствие кислорода в достаточном количестве препятствует переходу анатаз-рутил. Обнаруженные в композите фазы $\mathrm{Ti}_{4.5} \mathrm{O}_{5}$ и $\mathrm{Ti}_{6} \mathrm{O}_{11}$ обладают интересными свойствами. Фаза $\mathrm{Ti}_{4.5} \mathrm{O}_{5}$ является упорядоченной и более стабильной по сравнению другими фазами $\mathrm{TiO}_{y}[11]$, а фаза $\mathrm{Ti}_{6} \mathrm{O}_{11}$ отличается наличием кристаллографических плоскостей легкого скольжения. Наличие таких фаз оказывает влияние на механических свойствах композита и требует дальнейшего изучения.

Согласно данным работы [14], наноструктурированные композиты ГАП/ $\mathrm{TiO}_{2} 15$ масс. \% показывают лучшую биоактивность, чем подобные композиты с частицами микронного размера. Таким образом, наличие наноструктуры и присутствие фазы $\mathrm{TiO}_{2}$ в результате термообработки, согласно данным [14], положительно влияет на биосовместимые и биоактивные свойства композита.

Поскольку отжиг проводился в вакуумированных ампулах, можно предположить, что окисление монооксида титана происходит за счет ионов кислорода ГАП или за счёт молекул адсорбированной воды, сохранившихся после откачки в глубоких порах. По данным [15] при достаточно сложной координации атомов Са в ячейке ГАП образуются 75 связей Са-О (без учёта связей с кислородом иона гидроксила), 24 связи Р-О, 6 связей $\mathrm{Ca}-\mathrm{OH}^{-}$и 2 связи $\mathrm{OH}^{-}$. Вероятно, ионы кислорода для окисления монооксида титана поступают из гидроксильных групп ГАП. Согласно исследованиям авторов [16] при температуре $1200-1350^{\circ} \mathrm{C}$ отмечалось изменение фазового состава ГАП с образованием воды и перемещением её по порам. В других работах [17] обнаружено разложение исходного ГАП при температурах $1200-1350^{\circ} \mathrm{C}$ за счет удаления гидроксильных групп. В настоящей работе изменение фазового состава ГАП не обнаружено, процесс окисления монооксида титана требует дальнейшего изучения.

\section{4. Выводы}

При использовании нанопорошков ГАП и $\mathrm{TiO}_{y}$ удалось получить композиционный материал с нанодисперсной структурой, превосходящий по микротвёрдости и плотности керамику из ГАП. Свойства полученного композиционного материала зависят от стехиометрии и количества добавок $\mathrm{TiO}_{y}$. Поступление кислорода для окисления кубической фазы монооксида титана $\mathrm{TiO}_{y}$ до тетрагонального диоксида титана $\mathrm{TiO}_{2}$ (рутил, анатаз) происходит за счет разрушения гидроксильных групп в ГАП.
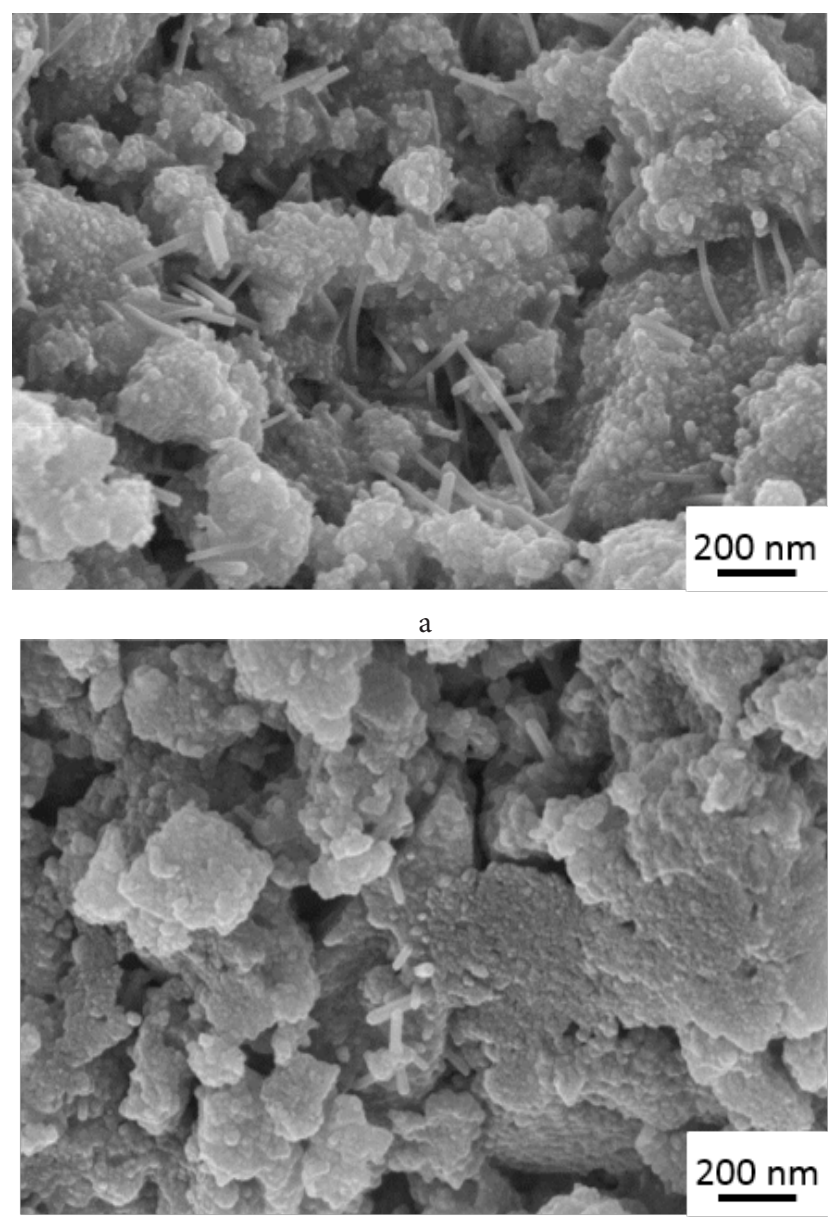

b

Рис. 2. РЭМ порошков нанокомпозита ГАП/ТіОу ГАП/10 масс. \% $\mathrm{TiO}_{1.23}$ после отжига а) при $400^{\circ} \mathrm{C}$ и b) при $600^{\circ} \mathrm{C}$.

Fig. 2. SEM of powders the HAp/TiOy composites after heat treatment: a) $\mathrm{HAp} / 10$ mass $\%$ of $\mathrm{TiO}_{1.23}$ after annealing at $400^{\circ} \mathrm{C}$; b) and at $600^{\circ} \mathrm{C}$.

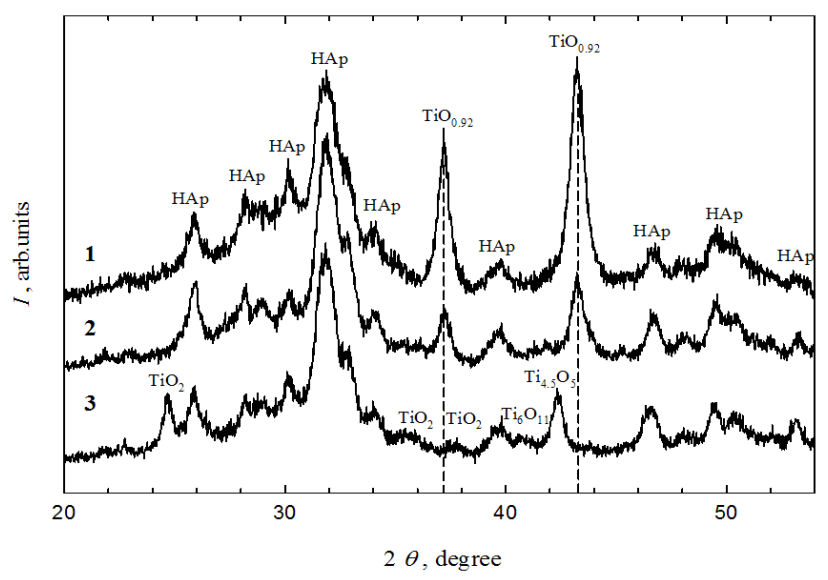

Рис. 3. Рентгенограммы для ГАП/ $\mathrm{TiO}_{0.92}-20$ мас. \% до отжига (1), после отжига при $400^{\circ} \mathrm{C}$ (2) и при $600^{\circ} \mathrm{C}$ (3). При $600^{\circ} \mathrm{C}$ наблюдаются дополнительные отражения, соответствующие $\mathrm{TiO}_{2}$ (анатаз), $\mathrm{Ti}_{4.5} \mathrm{O}_{5}$ и $\mathrm{Ti}_{6} \mathrm{O}_{11}$.

Fig. 3. XRD for $\mathrm{HAp} / 20$ mass $\% \mathrm{TiO}_{0.92}$ composite before annealing (1), after annealing at $400^{\circ} \mathrm{C}(2)$ and at $600^{\circ} \mathrm{C} \mathrm{(3).} \mathrm{After} \mathrm{annealing}$ at $600^{\circ} \mathrm{C}$, additional reflections corresponding to $\mathrm{TiO}_{2}$ (anatase), $\mathrm{Ti}_{4.5} \mathrm{O}_{5}$, and $\mathrm{Ti}_{6} \mathrm{O}_{11}$ have been observed. 
Показано, что использование $\mathrm{TiO}_{y}$ для армирования ГАП приводит к существенному снижению температуры полного упрочнения керамики и получению плотной нанокерамики без высокотемпературной обработки. Изменение стехиометрии и содержания $\mathrm{TiO}_{y}$ позволяет направленно изменять свойства композиционного материала, в частности, управлять процессами фазообразования.

Благодарность/Acknowledgements. Авторь выражают благодарность В.М. Скачкову, С.3. Назаровой и Х. Шретнеру (H. Schroettner) за помощь в проведении экспериментов. Работа выполнена при бинансовой поддержке Российского научного фонда (проект № 14-23-00025) в Институте химии твердого тела УрО РАН.

\section{Литература/References}

1. C. Bergmann, M. Lindner, W. Zhang, et al. Journal of the European Ceramic Society. 30 (12), 2563 - 2567 (2010).

2. C. Ergun, Z. Evis, T. J. Webster, F.C. Sahin. Ceramics International. 37, 971 - 977 (2011).

3. S. Ramesh, C.Y. Tanb, M. Hamdib, et al. International Conference on Smart Materials and Nanotechnology in Engineering. 6423 (64233A), 1 - 6 (2007).

4. S. Bose, S. Vahabzadeh, A. Bandyopadhyay. Materials Today. 16 (12), 496-504 (2013).

5. M. Tsukada, M. Wakamura, N. Yoshida, T. Watanabe. Journal of Molecular Catalysis A. 338, 18-23 (2011).

6. Wakamura M., Hashimoto K., Watanabe T. Langmuir. 19 (8), $3428-3431$ (2003).
7. M. Okada, T. Matsumoto. Japanese Dental Science Review 51, 85 - 95 (2015).

8. M. Okada, T. Furuzono. Sci. Technol. Adv. Mater. 13 (064103), 1 - 14 (2012).

9. S. P. Yatsenko, N. A. Sabirzyanov, RF Patent No. 2104924, application 96120482/25, 07.10.1996, published 20.02.1998. [С.П. Яценко, Н. А. Сабирзянов. Способ получения гидроксиапатита. Патент РФ №2104924, заявка 96120482/25, 07.10.1996, опубл. 20.02.1998].

10. A. A. Valeeva, A. A. Rempel, A.I. Gusev. Inorganic materials 37, 603-612 (2001) [А.А. Валеева, А.А. Ремпель, А.И. Гусев, Неорганические материалы, 37 (6), $716-727$ (2001)].

11. A. A. Valeeva, S.Z. Nazarova, A. A. Rempel, Physics of the Solid State. 58 (4), 771 - 778 (2016). [А. А. Валеева, С. 3. Назарова, А.А. Ремпель. ФТТ.58 (4), $747-753$ (2016)].

12. S. M. Barinov, V.S. Komlev. Nauka. Moscow. 2005, p. 204 [C. М. Баринов, Комлев В. С. М.: Наука, 2005. 204 с.]

13. S. M. Barinov. Russ Chem. Rev. 79 (1), $15-50$ (2010) [Баринов С. М. Успехи химии. 79 (1), 15 - 50 (2010)].

14. A. Farzin, M. Ahmadian, M.H. Fathi. Materials Science and Engineering C. 332251 - 2257 (2013).

15. V.P. Orlovskii, S.P. Ionov. Zhurnal Neorganicheskoi Khimii. 40 (12), 1961 - 1965 (1995). [В. П. Орловский, С.П. Ионов Ж. неорг. химии. 40 (12). $1961-1965$ (1995)).

16. T. Nakano, K. Kaibara, et al., Materials Transactions. 43 (12), 3105-3111 (2002).

17. D. Mondal, L. Nguyen, IH Oh, BT Lee. J Biomed Mater Res A. 101, (5), 1489 - 1501 (2013). 